\title{
Yield and fracture loci for a ductile cast iron EN-GJS-600-3 under biaxial stresses
}

\author{
M. Benedetti ${ }^{1}$, Tommaso Curtolo ${ }^{1}$, Michele Dallago ${ }^{1}$, Vigilio Fontanari ${ }^{1}$, and Danilo \\ Lusuardi $^{2}$ \\ ${ }^{1}$ Universita degli Studi di Trento Dipartimento di Ingegneria Industriale \\ ${ }^{2}$ Fonderie Ariotti Adro (BS) Italy
}

October 18, 2021

\begin{abstract}
Biaxial (axial and torsional loading) static tests were performed for the first time on EN-GJS-600-3 ductile cast iron tubular specimens obtained reproducing the solidification conditions typical of thick-walled castings. The experimental results were elaborated to determine the yield and fracture loci of the material, which exhibited significant deviations from those predicted by the Von Mises and Mohr-Coulomb criteria usually adopted for steels and grey cast iron, respectively. For this purpose, several alternative criteria proposed in the technical literature, some of them specifically devised for composite materials, have been calibrated and compared to account for the peculiar mechanical properties of this natural composite material.
\end{abstract}

\section{Hosted file}

Paper.docx available at https://authorea.com/users/441707/articles/542142-yield-andfracture-loci-for-a-ductile-cast-iron-en-gjs-600-3-under-biaxial-stresses 